\title{
The sociodemographic pattern of tobacco cessation in the 1980s: results from a panel study of living condition surveys in Sweden
}

\author{
Per Tillgren, Bo JA Haglund, Michael Lundberg, Anders Romelsjö
}

\begin{abstract}
Study objectives - To analyse the factors that determined whether or not people were successful in quitting tobacco during the 1980 s in Sweden.

Design - A logistic regression model was used for the analyses and included: education, marital status, socioeconomic group, social network, physical activities, cigarette consumption, and years spent smoking as independent variables. Men and women were analysed separately for smoking. A specific univariate analysis was also performed for men who used snuff.

Setting - Sweden.

Participants - A panel of 5104 randomised people aged 16-84 years was interviewed in 1980-81 and followed up in 1988-89 in the survey of living conditions undertaken by Statistics Sweden. The participation rate was $86 \%$. The panel included 1546 men and women who were daily smokers. There were 418 daily users of snuff among the men, and 129 men both smoked and used snuff.
\end{abstract}

Main results - Together $26 \%$ of women and $23 \%$ of men had quit smoking. Five per cent in both groups were new smokers. Among men, 26\% had quit using snuff and $5 \%$ had begun smoking. New snuff users among men were $5 \%$. In the multivariate analysis, unmarried men kept smoking at significantly higher rates (OR 2.1; 95\% CI $1.2,3.6)$, as did those men who smoked 11-20 cigarettes/day (OR 2.2; 95\% CI 1.5, 3.4), or more than 20 cigarettes/day (OR $2.8 ; 95 \%$ CI 1.4,5.7). Among women, smoking 11-20 cigarettes/day was also a significant factor (OR 3.3; 95\% CI 2.1,5.0). Men and women aged 25-44 were significantly more likely to continue smoking $(\mathrm{OR}=2.1 ; 95 \%$ CI 1.1,3.7, and 2.2; 95\% CI $1.2,4.4)$ as were those who had smoked for 20 years or more (OR 4.7; 95\% CI 2.0,10.8 and OR 2.5; 95\% CI 1.1,5.5, respectively). For women, low education (up to grade 9) was also a significant factor $(O R=2.5 ; 95 \%$ CI 1.2,5.1). Among men who had quit using snuff we did not find any values of significance.

Conclusions - One in four smokers had quit during the 1980s and a few started smoking (5\%). Some men quit smoking and started using snuff instead. For both sexes, the daily consumption of cigarettes, years spent smoking, and age were the most important determinants of successful quitting. In men, being married/ cohabiting was an important factor as was higher education in women.

( $\mathcal{F}$ Epidemiol Community Health 1996;50:625-630)

Since the 1960 s many scientific reports on smoking and health have been published. ${ }^{1}$ In the 1980s knowledge about the association between passive smoking and disease increased. ${ }^{2}$ It has also been shown that other tobacco products such as smokeless tobacco have a harmful effect on health. ${ }^{3}$

Increased knowledge of the adverse effects of tobacco on health has also resulted in a campaign against tobacco through health promotion and health education activities in western countries. There has been a decline in smoking prevalence in several western countries since the middle of the $1970 \mathrm{~s} .{ }^{4}$ In this decline, differences in the cessation pattern in terms of factors such as gender, age, educational/socioeconomic group, and cigarette consumption have been noticed..$^{5-8}$ In men, quitting has been achieved at a considerably faster rate than in adult women, but there are also gender differences in the factors that influence cessation. ${ }^{15910}$ Older smokers have been shown to have a higher cessation rate, ${ }^{11}$ but age is also a factor in the relationship between the amount of smoking and the success in quitting. ${ }^{12}$ People with more education have had more success quitting than those with less education. Some studies on cigarette consumption have shown that heavier smokers have quit less, while other studies have failed to demonstrate such a relationship. ${ }^{812}$

In Sweden, smoking prevalence among men has decreased since the end of the $1960 \mathrm{~s}$, while the decline among women began at the end of the 1970 s. ${ }^{13}$ Compared with other countries, Sweden has a low smoking prevalence $-25 \%$ of men are smokers. ${ }^{14}$ One reason for this may be the unique feature in Sweden of men (17\%) using smokeless tobacco in the form of oral moist snuff. ${ }^{15}$

Studies of smoking cessation have mainly been cross sectoral. However, there are very few studies in which the same individuals in a population have been followed up over a longer time period. This design alone makes it possible to assess presumptive determinants of quitting smoking. ${ }^{16}$ This report aimed to analyse the determinants of tobacco cessation during the 1980s in Sweden. 
Table 1 General characteristics of daily tobacco users who were members of a panel surveyed for the Swedish living conditions surveys in 1980-81 and 1988-89

\begin{tabular}{|c|c|c|c|c|}
\hline \multirow[t]{2}{*}{ Variables } & \multicolumn{2}{|c|}{$1980-81(n=1835)$} & \multicolumn{2}{|c|}{$1988-89(n=1632)$} \\
\hline & Men (\%) & Women (\%) & Men (\%) & Women (\%) \\
\hline \multicolumn{5}{|l|}{ Age (y) } \\
\hline $16-24$ & 18 & 22 & & \\
\hline $25-34$ & 25 & 25 & 26 & 27 \\
\hline $35-44$ & 22 & 21 & 27 & 29 \\
\hline $45-54$ & 11 & 15 & 19 & 29 \\
\hline $55-64$ & 13 & 11 & 9 & 19 \\
\hline $65-74$ & 11 & 6 & 11 & 13 \\
\hline$>75$ & & & 8 & 3 \\
\hline \multicolumn{5}{|l|}{ Education (y) } \\
\hline Low $(0-9)$ & 45 & 46 & 38 & 35 \\
\hline Medium (10-12) & 42 & 42 & 46 & 50 \\
\hline High (at least 13) & 13 & 12 & 16 & 15 \\
\hline \multicolumn{5}{|l|}{ Marital status } \\
\hline Married/cohabiting & 55 & 51 & 51 & 50 \\
\hline Unmarried & 37 & 30 & 36 & 26 \\
\hline Divorced & 7 & 14 & 10 & 18 \\
\hline Widower/er & 1 & 5 & 3 & 7 \\
\hline \multicolumn{5}{|l|}{ Socioeconomic group } \\
\hline Unskilled/semiskilled worker & 31 & 40 & 26 & 35 \\
\hline Skilled workers & 24 & 7 & 21 & 13 \\
\hline Assistant non-manual employees & 9 & 21 & 11 & 21 \\
\hline Intermediate non-manual employees & 11 & 9 & 14 & 12 \\
\hline Employed/self employed professionals & 8 & 4 & 10 & 7 \\
\hline Self employed/entrepreneurs & 8 & 4 & 11 & 3 \\
\hline Students & 6 & 10 & 2 & 3 \\
\hline Unemployed/early retired & 3 & 5 & 4 & 5 \\
\hline \multicolumn{5}{|l|}{ Physical exercise } \\
\hline Low (none or now and then) & 57 & 60 & 59 & 62 \\
\hline High (regularly; at least once/week) & 43 & 40 & 40 & 38 \\
\hline \multicolumn{5}{|l|}{ Social network/contact frequency } \\
\hline Low & 21 & 18 & 28 & 22 \\
\hline High & 79 & 82 & 72 & 78 \\
\hline
\end{tabular}

\section{Methods}

The data were based on a panel of participants from the survey of living conditions for 1980-81 and $1988-89 .{ }^{17}$ The survey was conducted by Statistics Sweden as an annual home interview survey of a random sample of the Swedish population aged $16-84$ years. In the $1980-81$ survey the total number of people interviewed was 14964 and in the 1988-89 survey 13295 subjects were interviewed. The participation rates were $86 \%$ and $79 \%$, respectively. During the 1988-89 survey, a random sample of participants who had taken part in the 1980-81 study was interviewed again. The panel consisted of about $40 \%$ of the whole sample. ${ }^{18}$ In total, the panel survey included 5104 subjects, with a participation rate of $86 \%$. In $1980-81$ there were 1546 daily smokers in the panel. Of the men, 418 used snuff on a daily basis and 129 both smoked and used snuff. General and tobacco specific characteristics of participants in the panel study are presented in tables 1 and 2 .

Table 2 Data on tobacco use in members of a panel surveyed for the Swedish living conditions surveys in $1980-81$ and $1988-89$

\begin{tabular}{|c|c|c|c|c|}
\hline \multirow[t]{2}{*}{ Variables } & \multicolumn{2}{|c|}{$\begin{array}{l}1980-81 \\
(n=1835)\end{array}$} & \multicolumn{2}{|c|}{$\begin{array}{l}1988-89 \\
(n=1632)\end{array}$} \\
\hline & Men & Women & Men & Women \\
\hline Daily smoker (\%) & 34 & 29 & 26 & 25 \\
\hline Cigarette & 27 & 28 & 23 & 25 \\
\hline Cigarillo & 1 & 0 & 1 & 0 \\
\hline Cigar & 1 & 0 & 1 & 0 \\
\hline Pipe & 6 & 0 & 4 & 0 \\
\hline Years smoking (mean) & 21.7 & 16.3 & 27.2 & 21.9 \\
\hline \multicolumn{5}{|l|}{ Consumption (mean) } \\
\hline Cigarettes/d & 15.3 & 12.6 & 15.2 & 13.0 \\
\hline Cigarillos/d & 7.6 & 0 & 4.1 & 0 \\
\hline Cigars/d & 4.5 & 0 & 6.4 & 0 \\
\hline Pipe/d $(50 \mathrm{~g})$ & 8.5 & 11.4 & 9.8 & 0 \\
\hline Boxes snuff/wk & $*$ & $*$ & 3.9 & 7.3 \\
\hline Daily snuff users & 17.0 & $t$ & 16.0 & 1.0 \\
\hline
\end{tabular}

* Data lacking; t the question was not posed in 1980-81.
There are no data on the exact year in which respondents stopped or started using tobacco; neither is information on relapses included in the data. In the 1980-81 survey, questions on snuff were only put to men. For smokers, the study is limited to daily smokers since questions directed to occasional smokers were not included in the 1980-81 survey. The analysis has mainly followed the WHO guidelines for tobacco surveys of the general population, and data on men and women have been presented separately. ${ }^{19}$

The outcome is based on all individuals who smoked daily or used snuff in the panel study at the time of the first interview (1980-81). During the second interview (1988-89) these individuals were divided into two groups: (1) those who still smoked/used snuff and (2) those who had stopped smoking/using snuff. This provided the outcome variable and the dependent variable. Presumptive determinants of quitting were age, education, marital status, socioeconomic status, social network, and physical activity.

With regard to age, the study population was grouped into 10-year groups. Education was divided into three subgroups: low (0-9 years), medium (10-12 years), and high (13 years or more). Marital status was classified into four subgroups. The socioeconomic status categorisation followed the official Swedish socioeconomic classification, comprising eight categories. ${ }^{20}$ Physical activity was divided into two subgroups: low (none or irregular) and high (regular, once a week or more). Social network was based on an index of contact frequency, ${ }^{21}$ based on five frequency questions of personal interaction with neighbours, coworkers, parents, children (if there are children), and other friends/acquaintances. For each variable the 80 th centile was determined. All individuals above this level were classified as having low contact frequency and were given the code 1 , while those below 80 had a higher contact frequency and were given the code 0 . After that a new variable was created by adding the five previous ones together (now consisting solely of zeros and ones), the result was a variable ranging from 0 (good social network) to 5 (poor social network). This process of centile estimation and $0 / 1$ coding was then repeated. Now only one variable with two categories remained: low (individuals with a low level of social relations) and high (individuals with a high level of social relations) as a measure of the social network of an individual.

The rate of quitting was estimated for all tobacco users. "Users" were defined as those who smoked cigarettes, cigarillos, cigars, or a pipe daily, or used smokeless tobacco (oral snuff). "Smokers" were defined as those who smoked tobacco daily and snuff users those who used snuff daily. Consumption of cigarettes was divided into three subgroups: 1-10 cigarettes/ day, 11-20 cigarettes/day, and 21 cigarettes/ day or more. We could not obtain the corresponding data for snuff consumption this was not included in the interview.

The first step in the analysis was to describe the relative changes (percentages) in tobacco 


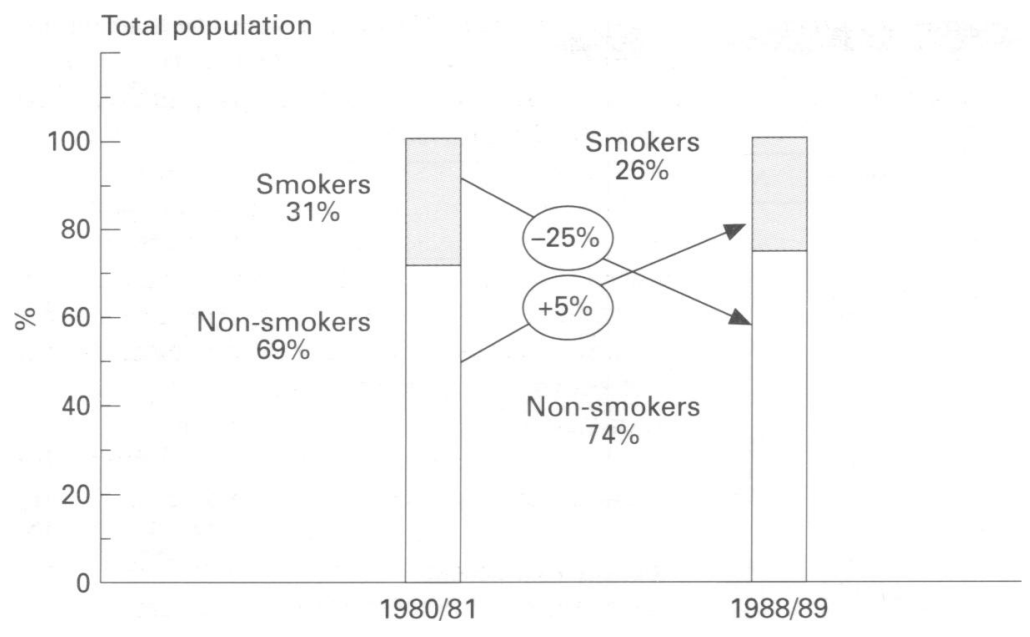

Figure 1 Percentages of daily smokers and non-smokers in a panel $(n=4951)$ of the Swedish population in 1980-81 and 1988-89. Source: Statistics Sweden's surveys of living conditions.

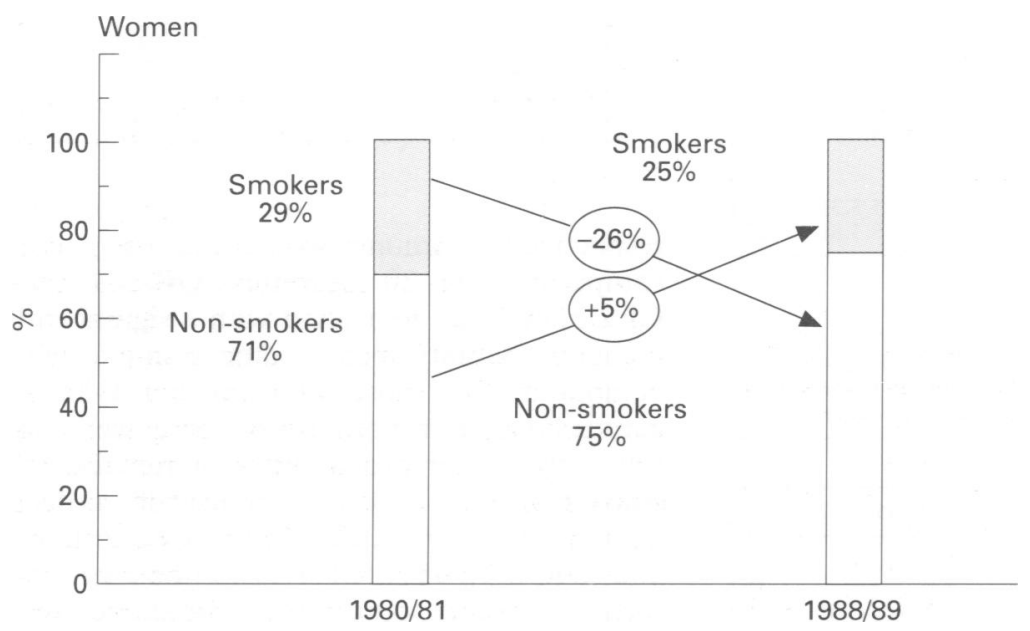

Figure 2 Percentages of daily smokers and non-smokers among women in a panel $(n=$ 2578 ) of the Swedish population in 1980-81 and 1988-89. Source: Statistics Sweden's surveys of living conditions.

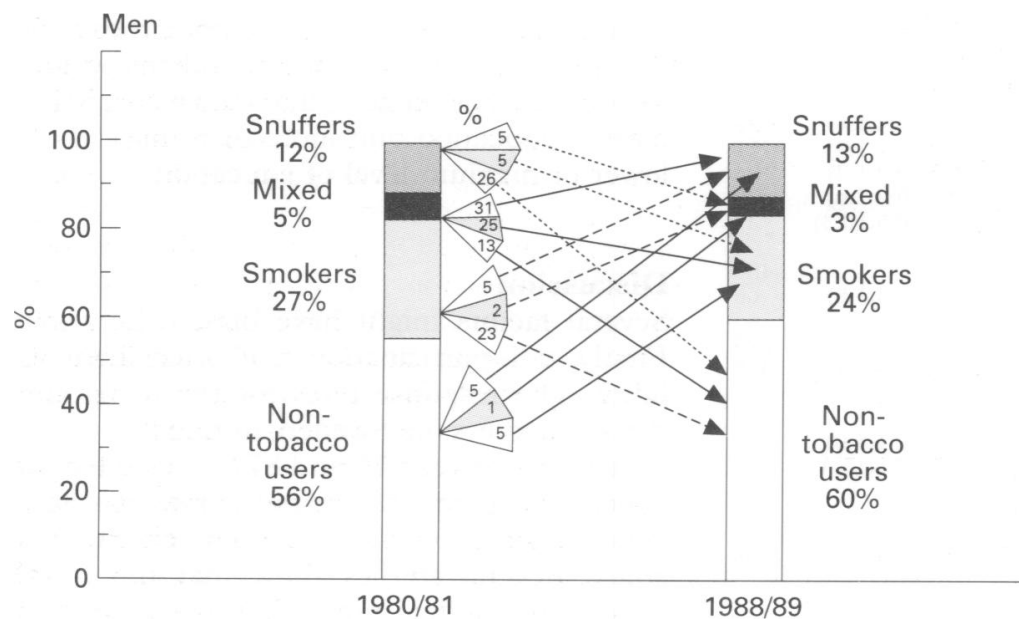

Figure 3 Percentages of daily snuff users ("snuffers"), smokers, and non-tobacco users among men in a panel $(n=2383$ of the Swedish population in 1980-81 and 1988-89. Source: Statistics Sweden's surveys of lining conditions

use among the participants in the panel in 1980-81 and 1988-89. The second step was to perform a univariate analysis to obtain a final model for multivariate logistic regression.
This final model included the following variables: age, education, marital status, socioeconomic group, physical activities, social network, cigarette consumption, and years spent smoking. In this analysis, which included only cigarette smokers, age was divided into three groups: 16-24 years, 25-44 years, and 45 years and older. Marital status included three groups: married/cohabiting, unmarried, and divorced. Socioeconomic groups were divided into six subgroups. The variable, "years of smoking", was subdivided into three groups: $0-6,7-19$, and 20 or more years. A specific univariate analysis was conducted among men who used snuff.

We have selected the reference groups based on our literature studies, taking into account factors previously shown to be of importance for successfully quitting smoking. Hence, the reference category of each respective variable serves as a comparison for the other groups in the variable. The calculations were done separately for each sex and the beta coefficient was converted to the odds-ratios (OR) with $95 \%$ confidence intervals ( $95 \% \mathrm{CI}$ ). For the logistic regression analysis, EGRET software was used, ${ }^{22}$ while other calculation and analysis work was done SAS - Statistic Analysis System. ${ }^{23}$

\section{Results}

The percentage of daily smokers fell from $30 \%$ in $1980-81$ to $25 \%$ in $1988-89$. In the panel study, $25 \%$ quit smoking and $5 \%$ started smoking (fig 1). In women, $26 \%$ quit smoking and $5 \%$ started smoking daily (fig 2), while in men $23 \%$ quit smoking and $26 \%$ quit using snuff. In the men, $5 \%$ of the snuff users began to smoke instead, while approximately $5 \%$ of smokers, besides smoking, also took up snuff. Of the men who had not previously used tobacco, $5 \%$ began smoking or using snuff (fig 3). The proportion of men who both smoked and used snuff dropped from $5 \%$ in $1980-81$ to $3 \%$ in $1988-89$. Between $1980-81$ and 1988-89 a decrease was noticed in all the variables studied in the first part of the analyses.

The univariate analysis showed that both men and women showed a significant difference in the probability of remaining a smoker related to daily consumption and the number of years spent smoking (table 3). No significant differences were seen in terms of age, but these were evident with regard to marital status. Married/ cohabiting men were more likely to quit than unmarried men. Just the opposite was observed for women. Significant differences were also noted among men with a low social network frequency, and in women with low physical exercise levels in 1980-81. Women with medium and low educational background were significantly more likely to remain daily smokers.

The multivariate analysis showed that unmarried men remained smokers at significantly higher rates than married/cohabiting men (OR $2.1 ; 95 \%$ CI $1.2,3.6$ ) (table 4 ). There was a significantly higher probability of remaining a smoker in men and women in the age group 25-44 years (OR 2.1; 95\% CI 1.1,3.7 and 2.3; 
Table 3 Univariate analyses of the risk of remaining a daily smoker eight years later in men and women members of a panel surveyed for the Swedish living conditions survey in 1980-81 and 1988-89. Values are odds ratios (OR) with 95\% confidence intervals (CI)

\begin{tabular}{|c|c|c|c|c|}
\hline \multirow[t]{2}{*}{ Variables } & \multicolumn{2}{|l|}{ Men } & \multicolumn{2}{|l|}{ Women } \\
\hline & OR $(95 \% C I)$ & No & OR $(95 \% C I)$ & No \\
\hline \multicolumn{5}{|l|}{ Age (y) } \\
\hline & 1.0 & 292 & & 236 \\
\hline $25-44$ & $1.3(0.9,1.8)$ & 387 & $1.4(0.9,2.1)$ & 349 \\
\hline $16-24$ & $0.8(0.5,1.3)$ & 117 & $0.6(0.4,1.0)$ & 165 \\
\hline \multicolumn{5}{|l|}{ Education (y) } \\
\hline High (at least 13) & 1.0 & 106 & & 91 \\
\hline Medium $(10-12)$ & $0.8(0.5,1.3)$ & 316 & $2.2(1.3,3.7)$ & 313 \\
\hline Low $(0-9)$ & $1.1(0.7,1.9)$ & 354 & $3.1(1.8,5.2)$ & 339 \\
\hline \multicolumn{5}{|l|}{ Marital status } \\
\hline Married/cohabiting & 1.0 & 433 & & 356 \\
\hline Unmarried & $1.4(1.0,2.0)$ & 259 & $0.5(0.3,0.7)$ & 213 \\
\hline Divorced & $1.7(0.9,3.3)$ & 64 & $1.1(0.6,2.0)$ & 98 \\
\hline \multicolumn{5}{|l|}{ Socioeconomic groups } \\
\hline \multicolumn{5}{|l|}{ Intermediate, professionals and other } \\
\hline higher non-manual employees & & 146 & & 81 \\
\hline Assistant non-manual employees & $1.9(0.9,3.7)$ & 68 & $0.9(0.5,1.7)$ & 133 \\
\hline Manual worker & $1.4(0.9,2.2)$ & 381 & $1.5(0.8,2.7)$ & 294 \\
\hline Self employed/entrepreneurs & $1.1(0.6,2.3)$ & 55 & $1.0(0.4,2.7)$ & 28 \\
\hline Students & $2.0(0.7,5.9)$ & 25 & $1.0(0.5,2.2)$ & 61 \\
\hline Unemployed/early retired & $1.4(0.5,4.5)$ & 21 & $2.8(0.8,10.8)$ & 29 \\
\hline \multicolumn{5}{|l|}{ Social network/contact frequency } \\
\hline High & 1.0 & 629 & 1.0 & 603 \\
\hline Low & $1.6(1.0,2.5)$ & 153 & $1.0(0.6,1.6)$ & 133 \\
\hline \multicolumn{5}{|l|}{ Physical exercise } \\
\hline High (regularly; at least once/week) & 1.0 & 306 & & 297 \\
\hline Low (none or now and then) & $1.2(0.9,1.7)$ & 469 & $1.4(1.0,1.9)$ & 447 \\
\hline \multicolumn{5}{|l|}{ Daily consumption cigarettes } \\
\hline $1-10$ & 1.0 & 248 & & 364 \\
\hline $11-20$ & $2.0(1.4,2.9)$ & 346 & $2.5(1.8,3.6)$ & 367 \\
\hline $21+$ & $2.7(1.4,5.4)$ & 72 & $3.8(0.8,24.4)$ & 16 \\
\hline \multicolumn{5}{|l|}{ Years of smoking } \\
\hline $0-6$ & 1.0 & 116 & & 158 \\
\hline $7-19$ & $2.4(1.5,3.9)$ & 274 & $2.1(1.4,3.3)$ & 314 \\
\hline $20+$ & $2.3(1.4,3.6)$ & 406 & $2.4(1.5,3.8)$ & 278 \\
\hline
\end{tabular}

Table 4 Multivariate analyses of the risk of remaining a daily smoker eight years later in men and women from the panel surveyed for the Swedish living conditions survey in 1980-81 and 1988-89. Values are odds ratios (OR) with $95 \%$ confidence intervals (CI)

\begin{tabular}{|c|c|c|c|c|}
\hline \multirow[t]{2}{*}{ Variables } & \multicolumn{2}{|l|}{ Men } & \multicolumn{2}{|l|}{ Women } \\
\hline & OR $(95 \% C I)$ & No & OR $(95 \% C I)$ & No \\
\hline \multicolumn{5}{|l|}{ Age (y) } \\
\hline $\begin{array}{l}45+ \\
25-44 \\
16-24\end{array}$ & $\begin{array}{l}1.0 \\
2.1(1.1,3.7) \\
1.9(0.7,5.0)\end{array}$ & $\begin{array}{r}149 \\
328 \\
73\end{array}$ & $\begin{array}{l}1.0 \\
2.3(1.2,4.4) \\
1.4(0.5,3.6)\end{array}$ & $\begin{array}{l}152 \\
295 \\
104\end{array}$ \\
\hline \multicolumn{5}{|l|}{ Education $(\mathrm{y})$} \\
\hline High (at least 13) & 1.0 & 81 & & 78 \\
\hline Medium $(10-12)$ & $0.6(0.3,1.1)$ & 255 & $1.4(0.8,2.7)$ & 259 \\
\hline Low $(0-9)$ & $0.8(0.4,1.6)$ & 214 & $2.5(1.2,5.1)$ & 214 \\
\hline \multicolumn{5}{|l|}{ Marital status } \\
\hline Married/cohabiting & 1.0 & 285 & 1.0 & 276 \\
\hline Unmarried & $2.1(1.2,3.6)$ & 211 & $0.6(0.3,1.2)$ & 193 \\
\hline Divorced & $1.5(0.7,2.9)$ & 54 & $1.0(0.5,1.9)$ & 82 \\
\hline \multicolumn{5}{|l|}{ Socioeconomic groups } \\
\hline \multicolumn{5}{|l|}{ Intermediate, professionals and other } \\
\hline Assistant non-manual employees & $1.6(0.7,3.4)$ & $\begin{array}{l}121 \\
558\end{array}$ & $\begin{array}{l}1.0 \\
0.7(0.3,1.4)\end{array}$ & $\begin{array}{r}74 \\
128\end{array}$ \\
\hline Manual worker & $1.1(0.6,1.9)$ & 309 & $1.4(0.7,2.9)$ & 271 \\
\hline Self employed/entrepreneurs & $0.7(0.3,1.6)$ & 38 & $0.5(0.2,1.4)$ & 24 \\
\hline Students & $2.0(0.4,8.9)$ & 15 & $2.2(0.7,7.0)$ & 29 \\
\hline Unemployed/early retired & $0.8(0.2,4.0)$ & 9 & $2.4(0.5,10.3)$ & 25 \\
\hline \multicolumn{5}{|l|}{ Social network/contact frequency } \\
\hline High & 1.0 & 482 & & 485 \\
\hline Low & $1.7(0.8,3.4)$ & 68 & $0.9(0.5,1.8)$ & 66 \\
\hline \multicolumn{5}{|l|}{ Physical exercise } \\
\hline High (regularly; at least once/week) & 1.0 & 227 & 1.0 & 223 \\
\hline Low (none or now and then) & $1.1(0.8,1.7)$ & 323 & $1.4(0.9,2.1)$ & 328 \\
\hline \multicolumn{5}{|l|}{ Daily consumption cigarettes } \\
\hline $1-10$ & 1.0 & 188 & & 245 \\
\hline $11-20$ & $2.2(1.5,3.4)$ & 296 & $3.3(2.1,5.0)$ & 292 \\
\hline & $2.8(1.4,5.7)$ & 66 & $3.1(0.6,15.4)$ & 14 \\
\hline \multicolumn{5}{|l|}{ Years of smoking } \\
\hline $0-6$ & 1.0 & 71 & 1.0 & 95 \\
\hline $7-19$ & $3.0(1.5,6.1)$ & 233 & $1.6(0.9,3.1)$ & 258 \\
\hline $20+$ & $4.7(2.0,10.8)$ & 246 & $2.5(1.1,5.5)$ & 198 \\
\hline
\end{tabular}

$95 \%$ CI 1.2,4.4, respectively). Low level of education, up to grade nine, among women also carried a significantly higher probability of remaining a smoker (OR 2.5; 95\% CI 1.2,5.1). Among men who smoked 11-20 cigarettes or more than 20 cigarettes per day, significantly more were still smoking in 1988-89 (OR 2.2; 95\% CI 1.5,3.4 and OR 2.8; CI 95\% 1.4,5.7,
Table 5 Univariate analyses of the risk of remaining a daily snuff user eight years later in men from the panel surveyed for the Swedish living conditions survey in

1980-81 and 1988-89. Values are odds ratios (OR) with 95\% confidence intervals $(C I)$

\begin{tabular}{|c|c|c|}
\hline \multirow[t]{2}{*}{ Variables } & \multicolumn{2}{|l|}{ Men } \\
\hline & OR $(95 \% C I)$ & No \\
\hline \multicolumn{3}{|l|}{ Age $(y)$} \\
\hline $45+$ & & \\
\hline $25-44$ & $0.9(0.5,1.7)$ & 194 \\
\hline \multirow{2}{*}{\multicolumn{3}{|c|}{ Education $(\mathrm{y})$}} \\
\hline & & \\
\hline High (at least 13) & & 46 \\
\hline Medium $(10-12)$ & $1.7(0.8,3.5)$ & 183 \\
\hline Low $(0-9)$ & $2.0(0.9,4.4)$ & 177 \\
\hline \multicolumn{3}{|l|}{ Marital status } \\
\hline $\begin{array}{l}\text { Married/cohabiting } \\
\text { Unmarried }\end{array}$ & 1.0 & 183 \\
\hline $\begin{array}{l}\text { Unmarried } \\
\text { Divorced }\end{array}$ & $0.8(0.5,1.3)$ & 189 \\
\hline Divorced & $1.6(0.4,7.6)$ & 14 \\
\hline \multirow{2}{*}{\multicolumn{3}{|c|}{$\begin{array}{l}\text { Socioeconomic groups } \\
\text { Intermediate, professionals and } \\
\text { other higher non-manual }\end{array}$}} \\
\hline & & \\
\hline & & 47 \\
\hline Assistant non-manual employees & $0.4(0.2,1.3)$ & \\
\hline Manual worker & $1.0(0.5,2.0)$ & 210 \\
\hline Self employed/entrepreneurs & $1.4(0.5,4.5)$ & 31 \\
\hline Students & $1.9(0.6,6.2)$ & 34 \\
\hline \multirow{2}{*}{\multicolumn{3}{|c|}{$\begin{array}{l}\text { Unemployed/early retired } \\
\text { Social network/contact frequency }\end{array}$}} \\
\hline & & \\
\hline High & & 317 \\
\hline \multirow{2}{*}{\multicolumn{3}{|c|}{ Physical exercise }} \\
\hline & & \\
\hline High (regularly; at least once/week) & & 205 \\
\hline or now and the & 1.4 & 202 \\
\hline
\end{tabular}

respectively). Among women, a daily consumption of 11-20 cigarettes (OR 3.3; 95\% CI 2.1,5.0) was associated with a significantly higher probability of continuing to smoke when compared with those who smoked 1-10 cigarettes/day. For both sexes there were significantly higher probabilities of remaining a smoker in those who had smoked for at least 20 years or more (OR $4.7 ; 95 \%$ CI $2.0,10.8$ and OR 2.5; 95\% CI 1.1,5.5 for men and women respectively) when compared with those who had smoked for 0-6 years.

In a univariate analysis of men who used snuff (table 5) there were no significant differences between those who had quit and those who still used it. In a multivariate analysis there were too few cases $(n=139)$ among those who had quit to obtain statistically reliable values. Yet our analysis suggests that men with a higher level of education quit more than those with a lower or medium level of education.

\section{Discussion}

Several factors might have biased the result. Firstly, non-participation may affect their validity. The response rates for the living conditions surveys in Sweden during the 1980s have been between 77 and $87 \% .{ }^{18}$ In the panel which we studied, the response rate was $86 \%$, which must be considered high for an interview study. Several studies show that those who "drop out" differ from study participants in terms of smoking habits, and that the rate of smoking is higher among non-responders, which may have influenced the results in this study. ${ }^{2425}$

The individual non-response to specific questions in the survey may also be due to bias, but this accounted for only a few per cent here. ${ }^{18}$ The living conditions survey has also been tested regular to confirm the validity of 
the measurement techniques and ensure that the high quality of the studies is maintained. This is imperative in order to maintain comparability over a period of time. ${ }^{18}$

Another source of bias can be found in the final model used for the multivariate analysis (table 4). Not all participants had answered all of the questions included in the final model. The non-response rates were $30 \%$ for men and $26 \%$ for women when the results were compared with results from the univariate analysis (table 3). A separate analysis was therefore undertaken to study effects of selection of participants included in the final model. Comparison of results from the univariate and the multivariate analyses showed overestimation of the OR for men in the age groups 16-24 and 25-44, as well as for years smoked in the 7-19 years and more than 20 years groups. A tendency to underestimate was noted in the socioeconomic groups. For women there was an underestimation of results in relation to education level and years smoked. An overestimation was found for daily cigarette consumption in the 11-20 cigarettes/day group.

Another kind of bias which may have influenced our results is that information about smoking and snuff status was not checked with a biochemical assay for tobacco in body tissues, eg cotinine determination in plasma, saliva, or urine. However, self reports have been found to be valid in population studies. ${ }^{26}$ Interviewer administered questionnaires, which were used in our study, have yielded higher estimates of sensitivity and specificity for smoking status than self administered questionnaires. ${ }^{27}$

A panel study with repeat interviews may cause bias, as the interest of the respondent may have been aroused during the first visit and be influenced by the questions posed. ${ }^{28}$ However, neither the participants nor the interviewer knew that there would be further interviews. Of all the questions in this study, very few concerned tobacco habits. Another problem in interpreting the results of a panel study is maintaining complete control of all explanatory variables, as these may change with time. ${ }^{28}$ In this study, this might be true for the following variables; education, marital status, socioeconomic group, social network, and physical exercise, as shown in tables 1 and 2 .

For over two decades the adult population of the western world has increasingly been quitting tobacco This trend was substantiated by our study, in which one in four smokers had quit, while only $5 \%$ had taken up smoking. Most men and women had started smoking before the age of 30 . Our findings show that those who had taken up smoking were somewhat older than other studies suggest and that few people began smoking after the age of $20 .{ }^{29}$

When we study the change patterns for women and men, we find a significant difference in consumption patterns between the sexes. Consumption of tobacco among women in Sweden is mainly through cigarette smoking, while approximately $17 \%$ of men also use moist snuff. ${ }^{30}$ Among the men, $26 \%$ of the daily snuff users had quit, while $5 \%$ took up smoking. Of the men who had previously smoked, $5 \%$ began using snuff instead. Of the men who had previously not used any tobacco, the same fraction - $5 \%$ - took up snuff as smoking, $5 \%$ respectively. Thus, unlike men, women do not start using other tobacco products as substitutes after they give up smoking.

Our findings from the multivariate analysis are consistent with results from several other studies - ie, that there are different background factors for both women and men in quitting smoking. ${ }^{59}$ Our study indicated that for both sexes those who smoked fewer cigarettes per day had a higher rate of quitting than those who smoked more. One important reason for this may be that those who smoke more frequently are often assumed to be more strongly addicted to nicotine. ${ }^{8} \mathrm{~A}$ seemingly contradictory result is that those over 45 years old had quit at higher rates than younger people, while those who had smoked the most years had quit less. The reasons for the risk increasing with the number of years spent smoking may be that many younger people have been smoking a fairly long time. Other studies have also shown that smoking habits may differ in various age cohorts. $^{12}$

Educational level has been shown to be a significant background factor in quitting smoking. ${ }^{4}$ This was also noted in our analysis, since fewer women with a low education level had quit. For men, being married or cohabiting was shown to be a positive factor in quitting, while those who lived alone did not quit to the same extent.

Other studies have shown that social network plays a significant role in successfully quitting smoking. ${ }^{213132}$ In our study no such relations were found in the multivariate analysis. One reason for this may be that the questions included in our social network index were based upon the person's contact frequency and not upon other factors such as social anchoring and social support. ${ }^{213233}$ If, however, marital status is also considered as a factor influencing social network and support, sex related differences are seen, with lower quitting rates for those who are male and unmarried (OR 2.1).

Are our results consistent with those from earlier studies in Sweden? Few panel studies have been carried out and published, but one study of a Swedish population sample aged 15-75 years interviewed in 1974 and 1981, showed that overall tobacco consumption was the most important variable in explaining the variance; which is in agreement with our study. The probability of smoking cessation increased by $40 \%$ if the subject smoked fewer than 10 cigarettes per day compared with those who smoked 10 or more cigarettes per day. ${ }^{34}$ Our study also showed that socioeconomic factors have only marginal effects on quitting smoking. We conclude that the factors which were important for quitting smoking in 1974-81 also apply to our study covering the period 1980-89.

Over the past two decades there has been a reduction in daily smoking in the western world. ${ }^{4}$ Several factors may have influenced this development - increased knowledge about the health hazards of tobacco use, better smoking cessation services through health care and 
occupational health centres, and the introduction of nicotine substitutes. Health policies and governmental regulation initiatives, including warning labels on tobacco products and in advertisements, as well as the increasing tax on tobacco during the 1980 s have been become more forceful. ${ }^{35}$ At the regional level, county councils in Sweden have taken a more active role in tobacco prevention work through a number of initiatives. Opportunities for smoking have also been limited by an increase in the number of public workplaces and other premises that have banned smoking.

We can also observe, however, that the general decline of tobacco use in Sweden during the 1980 s was different in men compared with women. Men experienced a greater decline since fewer took up smoking at an early age. The prevalence of daily smokers among boys aged $15-16$ was $12 \%$ compared with $17 \%$ among girls. ${ }^{36}$ However, $14 \%$ of young boys aged 15-16 use moist snuff daily. Snuff use is very uncommon among young women. This explains why the decline in tobacco consumption for men, seen as a whole, has not been as great as it has been for smoking alone. Some of the men who quit smoking took up snuff instead. In our study it was shown that it was just as common for those who started using tobacco after the age of 16 to start using snuff as tobacco, while women only took up smoking.

In our study that one in four smokers had quit during the 1980 s and few started smoking (5\%). Some men who quit smoking and had not previously used tobacco started using snuff instead. For both sexes, the daily consumption of cigarettes, years spent smoking, and age were the most important determinants for successful quitting. For men ever being married or cohabiting was important, as was having a higher education for women. Future tobacco prevention efforts should be concentrated on motivating and supporting groups who have not succeeded in quitting by themselves. In order to reduce tobacco use further, measures should be directed at young people, as they are responsible for a large part of the net increase. Programmes targeted at snuff users should also be developed.

1 US Department of Health and Human Services. Reducing the health consequences of smoking: 25 years of progress. $A$ the health consequences of smoking: 25 years of progress.
report of the Surgeon General. US Department of Health report of the Surgeon General. US Department of Health
and Human Services, Public Health Service, Centers for and Human Services, Public Health Service, Centers for
Disease Control, Center for Chronic Disease Prevention and Health Promotion, Office on Smoking and Health, 1989. Publication no (CDC) 89-8411.

2 Jarvis MJ. Passive smoking. In: Heller T, Bailey L, Pattison $S$ eds. Preventing cancers. Buckingham: Open University Press, 1992; 121-9.

3 US Department of Health and Human Services. Smokeless tobacco or health. An international perspective. US Department of Health and Human Services, Public Health partment of Health and Human Services, Public Health Services, National Institute of Health, Nation

4 Pierce JP. International comparisons of trends in cigarette smoking prevalence. Am f Public Health 1989;79:152-7.

5 Waldron I. Pattern and causes of gender differences in smoking. Soc Sci Med 1991;32:989-1005

6 McWhorter WP, Boyd GM, Matsson ME. Predictors of quitting smoking: The NHANES follow up experience. $\mathcal{F}$ Clin Epidemiol 1990;43:1399-405.

7 Pierce JP, Fiore MC, Novotny TE, Hatziandreu EJ, Davis RM. Trends in cigarette smoking in the United States.
Educational differences are increasing. $¥ A M A 1989 ; 261$ : 56-60.

8 Giovanni GA, Shelton DM, Schooley MW. Trends in cigarette smoking cessation in the United States. Tobacco Control 1993;2(suppl): S3-S10.

9 Cullen JW. Tobacco use: Prevention and control. Israel $\mathcal{f}$ Med Sci 1986;22:283-300.

10 Batten L. Respecting sameness and difference: taking account of gender in research on smoking. Tobacco Control $1993 ; 2: 185-6$

11 Fiore MC, Novotny T, Pierce JP, et al. Methods used to quit smoking in the United States. Do cessation programs help? $\mathcal{F} A M A$ 1990;263:2760-5.

12 Coambs RB, Li S, Kozlowski LT. Age interacts with heaviness of smoking in predicting success in cessation of smoking. Am $\mathcal{f}$ Epidemiol 1992;132:240-6.

13 Tobakslag. Betänkande av tobaksutredningen. (Tobacco Act. Report of the Tobacco Committee). Stockholm: Allmänna Förlaget, 1990. SOU 1990:29.(In Swedish).

14 WHO. Country reports. Fourth WHO seminar for a tobaccofree Europe. Tobacco and the law: litigation as a public health free Europe. Tobacco and the law: litigation as a public health tool, Skövde, Sweden 2-4 June, 1994.

15 Nordgren P, Ramström L. Moist snuff in Sweden - tradition and evolution. Br f Addict 1990;85:1107-12.

16 Freund KM, Agostino RBD, Belanger AJ, Kannel WB, Stokes J. Predictors of smoking cessation: The Framingham study. Am $\mathcal{F}$ Epidemiol 1992;135:957-64.

17 Vogel J, Andersson L-G, Davidsson U, Häll L. Inequality in Sweden. Trends and current situation. Living conditions 1975-85. Stockholm: Statistics Sweden, 1988. Report no 58.

18 Statistiska Centralbyrån. Levnadsförhållanden. Teknisk rapport avseende 1984-85 års, 1986-87 års och 1988-89 års undersökningar av levnadsförhållanden, appendix 13. (Living undersokningar av levnadsforhallanden, appendix 13. (Living for 1984-85, 1986-87 and 1988-1989). Stockholm: Statfor 1984-85, 1986-87 and 1988-1989). St
istiska Centralbyrån, 1991. (In Swedish).

19 WHO. Guideline for the conduct of smoking surveys of the general population. Geneva: WHO, 1983. Document Ho7sMO/83.4.

20 Statistiska Centralbyrån. Socioekonomisk indelning. (Swedish socio-economic classification). Stockholm: Statistiska Centralbyrån, Meddelande i samordningsfrågor, 1982:4. (Summary in English).

21 Östergren P-O. Psychosocial resources and health. With special reference to social network, social support and cardiovascular disease. Malmö: Department of Community Health Sciences, Lund University, 1991. PhD thesis.

22 Statistics and Epidemiology Research Corporation. EGRET, Epidemiological graphics, estimation, and test. Seattle: StatEpidemiological graphics, estimation, and test. Seattle: Stat
istics and Epidemiology Research Corporation, 1990.

23 SAS Institute Inc. SAS user's guide: statistics version 6 edition. Cary, NY: SAS Institute Inc, 1985.

24 Boström C, Hallqvist J, Haglund BJA, Romelsjö A, Svanström L, Diderichsen F. Socio-economic differences in smoking in an urban Swedish population. Scand $\mathcal{f}$ Soc Med 1993;21:77-82.

25 Criqui MH, Barret-Connor E, Austin M. Difference between respondents and non-respondents in a populationbased cardiovascular disease study. Am $\mathcal{f}$ Epidemiol 1978; 108:367-72.

26 US Department of Health and Human Services. The health benefits of smoking cessation. A report of the Surgeon General. US Department of Health and Human Services, Public Health Service, Centers for Disease Control, Center for Chronic Disease Prevention and Health Promotion, Office on Smoking and Health, 1990. DHHS Publication No (CDC) 90:8416.

27 Patric DL, Cheadle A, Thompson DC, Dier P, Koepsell T, Kinne ST. Validity of self-reported smoking: A review and meta-analysis. Am f Public Health 1994;84:1086-93.

28 Kasorzyk D, Kalton G, Sing MP. Panel surveys. New York: John Wiley \& Sons, 1989

29 McGinnis JM, Shopland D, Brown C. Tobacco and health: Trends in smoking and smokeless tobacco consumption in the United States. Ann Rev Public Health 1987;8:441-67.

30 Socialstyrelsen. Folkhälsorapport 1991. (Public Health Report 1991). Stockholm: Allmänna förlaget, 1991. SoS rapport no 11. (In Swedish).

31 Berkman LF, Symne SL. Social networks, host resistance and mortality: A nine-year follow-up study of Alameda county residents. Am F Epidemiol 1979;109:186-204.

32 Hansson BS, Isacsson S-O, Janzon L, Lindell S-E. Social support and quitting smoking for good. Is there an association? - Results from the population study "Men born in 1914", Malmö, Sweden. Addict Behav 1990;15:221-33.

33 Helminen A, Halonen P, Rankinen T, Nissinen A, Rauramaa R. Validity assessment of social support index. Scand $\mathcal{f}$ Soc Med 1995;23:66-74.

34 Lundberg O, Rosén B, Rosén M. Research note. Who stopped smoking? Results from a panel survey of living conditions in Sweden. Soc Sci Med 1991;32:619-22.

35 Magnusson S, Nordgren P. Om tobak. Bakgrund och kommentarer till tobakslagen. (On tobacco. Background and commentaries to the Tobacco Act). Stockholm: Fritzes, 1994. (In Swedish).

36 Andersson B, Hibell B. Skolelevers drogvanor 1993. Resultat frän riksundersökningen $i$ ärskurs 6 och 9. (Substance abuse among school children 1993. Results from a national survey in grade six (aged 12-13) and grade nine (aged kotikaupplysning, rapportserie, 1993:36. (In Swedish). 